\title{
DISCLAIMIRR
}

This report was prepured as an mocount of work eponeored by an apency of the United Staten Governmeat. Neither the Unised Sintes Government nor any axency thereof, nor any of their employes, makes any warraty, express or implied, or asoumes any kegl linbility or responibility for the sccuracy, completeacen, or usefulnew of any information, apparntus, product, or proces diecloned, or represents that its une would not infringe privately owned rights. Reference herein to any apecific comnercill product, process, or service by trade name, trademark, manufecturer, or otherwive does not necesurily constitute or imply its endorsement, recommeadation, of feroring by the United States Government or any afency thereof. The viem and opinions of anthors expreaned berein do not necesurily itate of reflect those of the United States Government or any aveacy thereof.

\section{NEUTRON IRRADIATION OF SUPERCONDUCTORS AND DAMAGE ENERGY SCALING OF DIFFERENT NEUTORN SPECTRA}

Peter A. Hahn

Harald W. Weber

Michael W. Guinan

Robert C. Birtcher

Bruce S. Brown

Lawrence R. Greenwood

This paper was prepared for submittal to

Advances in Cryogenic Engineering

CEC/ICMC

Massachusetts Institute of Technology

Cambridge, MA August 12-16, 1985

August 1985

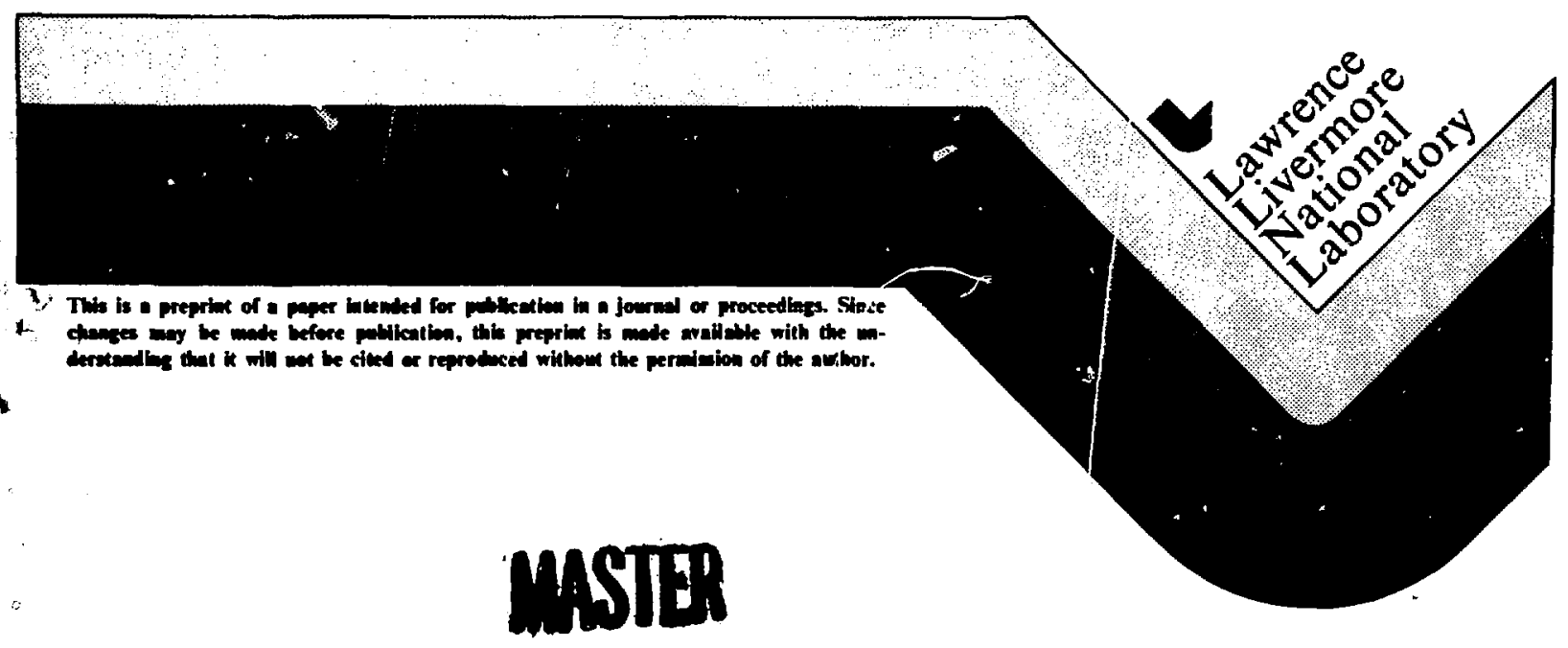


DCRL--93186

DE85 017834

\title{
REUTRON IRRADIATION OF SUPERCONDUCTORS AMD DAMAGE
}

\section{EHERGY SCALIKG OF DIFFERENT NEUTRON SPECTRA}

\author{
Peter A. Hahn* and Harald W. Weber \\ Átoninatitut der Österreichischen Univ rsitäten \\ Wien, Austria \\ Michael พ. Guinan \\ Lawrence Livermore Mational Laboratory, Livernore \\ California \\ Robert C. Birtcher, Bruce S. Brown and \\ Lawrence R. Greenwood \\ Argonne Hational Laboratory, Argonne, Illinois
}

\section{ABSTRACT}

Three different neutron sources were used to irradiate iientical sets of MbTi superconductors up to sbout half the lifetine dose of a superconducting magnet in a fusion reactor. Based on a careful source characterization of the TRIGA Hark-II reactor in Vienna, the opallation neutron source IPNS at Argonne and the $14 \mathrm{MeV}$ neutron source RTiS-II at Livermore, the danage energy croas sections were calculated for four different types of MbTi alloys $(42,46.5,49$ and 54 th Ti). The experimental results on the variatiots of critical current densities $j_{c}$ with neutron dose are found to scale within the experinental uncertainties with the appropriate damage eneryy cross sections. This first explicit proof of damage energy scaliag for $j_{c}$-variations in superconductors is considered to be most valuable for the evaluation of radiation dange in superconductors under fusion reactor conditions.

\section{INTRODUCTION}

The primary objective of this work was to detexwine the effects of neutron irradiation obtained from different sources on the critical current density $j_{c}$ in comercially anufactured mbi superconductors suited for magnet construction in future fusion reactors. The crucial question raised by nagnet designers, whether the results fron various irradiation experinents obtained so far can be directly applied to the superconductor at the magnet location, auggested the experinental verification of the danage energy concept developed in recent years. This nethod is increasingly used to characterize and conpare the results of different neutron irradiation studies:

*Present address: Muclear Chenistry Division, Lawrence Livernore Nationel Laboratory, Livereore, Californis 
The chenges of the critical parameters of a superconductor such as $T_{c}$, $\mathrm{H}_{\mathrm{c} 2}$ and $\mathrm{j}_{\mathrm{c}}$ during irradiation is primarily due to the total danage deposited in the eaterial. The calculation of this quantity, measured in displacements per aton (dpa) or more practically ev/atom, requires a complete knowledge of the neutron spectrun, the fluence obtained during irradiation, the differential neutron cross sections and the primary recoil distribution of the irradiated material. In metals, a significant contribution to the total damage is caused by high energy neutrons; hence, the flux of several irradiation facilities is frequently quoted for energies greater than 0.1 or grester than $1.0 \mathrm{MeV}$, respectively. A large fraction of the incident neutron energy goes into electroric excitation, activation and theral vibrations of the lattice atoms rather than into production of displacement cascades. Moreover, the majority of produced defects, any they be point defects or entire cascades, are subject to recombination during the process of formation, thus the remperature maintained during irradiation affects the number of "surviving" defects. An adequate model of the interaction between neutrons and the atoms of the irradiated metal has been discussed previously.

Based on the knowledge of differential elastic and inelastic neutron scattering cross sections, $\sigma(\mathrm{B})$, the primary recoil energy distribution $T(E)$ for each individual energy-flux group of a given neutron spectrun has been calculated uring the SPECTER-computer code." The total displacement energy cross section $\langle\sigma \cdot T\rangle$ averaged over all neutron energies can be expressed as

$$
\frac{\int \sigma(E) \cdot T(E) \cdot \frac{d \phi}{d E} d E}{\int \frac{d \phi}{d E} d E}
$$

Multiplication of this quantity with the actual fluence obtained during irradiation yields the average energy per aton deposited for defect production. As indicated earlier, the fluence ( $f$ lux $\phi x$ irradiation time $t$ ) may be specified for $\mathrm{E}>0.1$ or $\mathrm{E}>1.0 \mathrm{MeV}$, respectively. The resulting product, however, remains congtant for the damage energy cross sections are scaled accordingly.

If there is more than one element in the irradiated sanple, which is the case in the investigated NbTi alloys, one hag to calculate the contribution of each element to the total damage energy cross section. Linear scaling with the atomic percentage $c_{i}$ is employed during sumation:

$$
\langle\sigma \cdot \mathrm{T}\rangle=\sum_{\text {Alloy }}<\sigma \cdot \mathrm{T}_{1} \cdot \mathrm{c}_{1}
$$

More advanced theoretical models for binary systems ${ }^{5}$ indicate that in the present case, this simplification does not represent a significant source ef error. All irradiations of the $\mathrm{HbT} i$ superconductors described in this work have been carried out at roow temperature. Irradiation experiments at $5.0 \mathrm{~K}$ with subsequent annealing cycle to $300 \mathrm{~K}$ have been conpleted and vill be published. 6

\section{EXPERIMENT}

\section{Materials}

All WhTi conductors vere menufactured by Brown Boveri \& CIE/Switzerland. Two identical sets containing 14 aingle core conductors and three multifilamentary conductors have been selected for the irradiation programs at 
IPNS/Argonne and BTIS-II/Livernore. A detailed characterization of all irradiated naterials is given in Ref. 7. One of the multifilanentary conductors has been developed for the LCT (Large Coil Test) progran currently carried out at Oak Ridge National Laboratory. An additional set has been irradiated earlier in the IRIGA Mark-II reactor in Vienna, ${ }^{7}$ All single core conductors have undergone an annealing step at $400^{\circ} \mathrm{C}$ prior to final cold work wich was varied $(0-917)$ as well as the Ti concentration $(42,49$ and 54 wt\% corresponding to 58,65 and 70 atz respectively). Whereas the Tirich amples ( $54 \mathrm{wt} \mathrm{Ti}$ ) exhibit significantly higher current densities in manetic fields $u_{\tilde{y}}$ to $6 \mathrm{~T}$ than aterials with 42 wtz $\mathrm{T} i$, their perfornance at the projected field of $8 \mathrm{~T}$ is declining rapidly because of their lover $\mathrm{B}_{\mathrm{c} 2}$. For the present standard conductors, including the LCT-conductor, a composition of 46.5 wt $(63 \mathrm{at} z) \mathrm{T}$ i hes been chosen. The single core conductors were all $0.4 \mathrm{~m}$ in diaweter, their Copper to superconductor ratio (with respect to volume) was about $1: 1$. All axples were prepared to meet the requirements of the experimentel setup measuring $j_{c}$ and the apacial congtraints in the itradiation facilities. Straight pieces, 47 in lengt?, vere cut and polished to rewove the oxide layer from the copper stabilizer. Thin potential lead were soldered onto each sanple with a relatively smell gaugs length of 6 to avoid excessive fluence gradients along the sample arising from the strong inhonogenious flux distribution inherent to all eccelerator based neutron sources.

\section{Neutron Irradiation}

One set of samples has been irradiated with $14.6 \mathrm{MeV}$ neutrons at RTNS-II in 3 cycles to fluences of $2.22 \times 10^{21}, 4.26 \times 10^{21}$ and $5.82 \times 10^{21}$ $\mathrm{n} / \mathrm{m}^{2}$ averaged over all spcinens. Simall $\mathrm{kb}$ foils attached to the samples were used to monitor the fluences. After each cycle the whole batch was shipped to Argonne for je-measurements. Before the second and third cycle the positions of the samples have been rotated with respect to the bean spot of the target in order to cowrensate the differences in neutron fluence between individual asmles.

Another set has been irradiated at ambient tenperature at IPHS in 3 cycles up to fluences $\left(E>0.1\right.$ MeV) of $0.53 \times 10^{22}, 0.86 \times 10^{22}$ and $1.96 \times 10^{22} \mathrm{n} / \mathrm{m}^{2}$ with spallation neutrons. These numbers are based on an activation analyois of $\mathrm{Hi}$ dosimetry wires attached to the sanples during irradiation.

The regults on an identical set of naterisl irradiated in the TRIGAreactor were already reported by kardai et .11 .7 and are used for confarison. Although there have been six irradiation cycles carried out up to a total fluence of about $1.75 \times 10^{23} \mathrm{n} / \mathrm{m}^{2}$, only data for the first three cycles, $8.8 \times 10^{20}, 8.8 \times 10^{21}$ and $4.4 \times 10^{22} \mathrm{a} / \mathrm{m}^{2}(\mathrm{E}>0.1 \mathrm{MeV})$, are quoted in this work because the results at higher fluences exceed the range of data obtained from the experinents at RTMS-II and IFiss. It should be noted that the absolute errors in deteraining the neutron fluence are typically estimated at $10 \%$.

\section{$j_{c}$-Measurements}

After each irradiation cycle the critical current densities have been measured at $4.2 \mathrm{~K}$ as a functiton of the magnetic field (perpendicular to the wire axis) in the range between 1.0 and $8.0 \mathrm{~T}$ in steps of $0.5 \mathrm{~T}$. Each sample was mounted free from mechanical stress onto a smple holder in a manner to prevent any movenent caused by the Lorentz force when magnetic fields were present during $j_{c}$ measurement. A standard four probe technique vas employed to deteraine $j_{c}$ applying a voltage criterion of $50 \mathrm{\mu v} / \mathrm{cm}$. The implications of "defining" $j_{c}$ by wans of a certain voltage criterion have been discussed earlier." In the case of single core conductors, this 
does not represent a mojor problen for their transition from the superconducting to the normal state occurs quite rapidly in contrast to miltifilaentary conductors with a rather mooth I-V characteristic near $j_{c}$.

\section{MALTSIS}

\section{Meutron spectre}

Besed on elastic and inelastic scattering cross sections, i.e. nuclear data for $(n, x n),(n, \alpha)$ and $(n, \gamma)$, reactions listed in ENDF-B/,${ }^{3}$ the diffarential fluxes $d \phi / d E$ in 211100 energy groups have been calculated using the STAXS'L conputer code." An ectivation enalysies ${ }^{10}$ of the central irradiation thimble of the TRIGA Mark-II reactor in Vienne with subsequent STAYS'L evaluation revealed no ignificant deviarion from the spectrum originally apecified by the contractor General Atonica/San Diego. The neutron spectra of the irradiation facilities used are illuatrated in Fig. 1. where the flux per unit lethargy, $d \phi / d l n E$, is plotted on a linear scale. In this representation the area under the pectrun or sections thereof is directly proportional to the total number of neutrons or its fraction within a secified energy range.

In characterizing the neutron spectra of the three facilities, one hos to deal with different source trengths which are summarized in Table 1. The apectra have been noralized in a way that the total of all group fluxes is equal to 1.0 hich is useful if one is conparing the percentage of neutrons within a particular energy range between different neutron sources regardless of their total flux. In addition, the theoretically modelled sectra at the aagnet location for the STARFIRE ${ }^{11}$ and MARS (Mirror Advanced Reactor Study) ${ }^{12}$ designs are presented in Fig. 2., viewing the regions with the leat amount of shielding between the plaman and the superconductor, which can be regarded as a worst case assumption.

Denage energy cross sections averaged over the entire neutron spectrun or scaled to $E>0.1$ or E $>1.0 \mathrm{MeV}$ respectively, have been calculated for pure $\mathrm{Mb}, \mathrm{Ti}$ and several alloys. The numbers listed in Table 2. are applicable to fluences quoted for $E>0.1 \mathrm{MeV}$. The damage energy cross sections

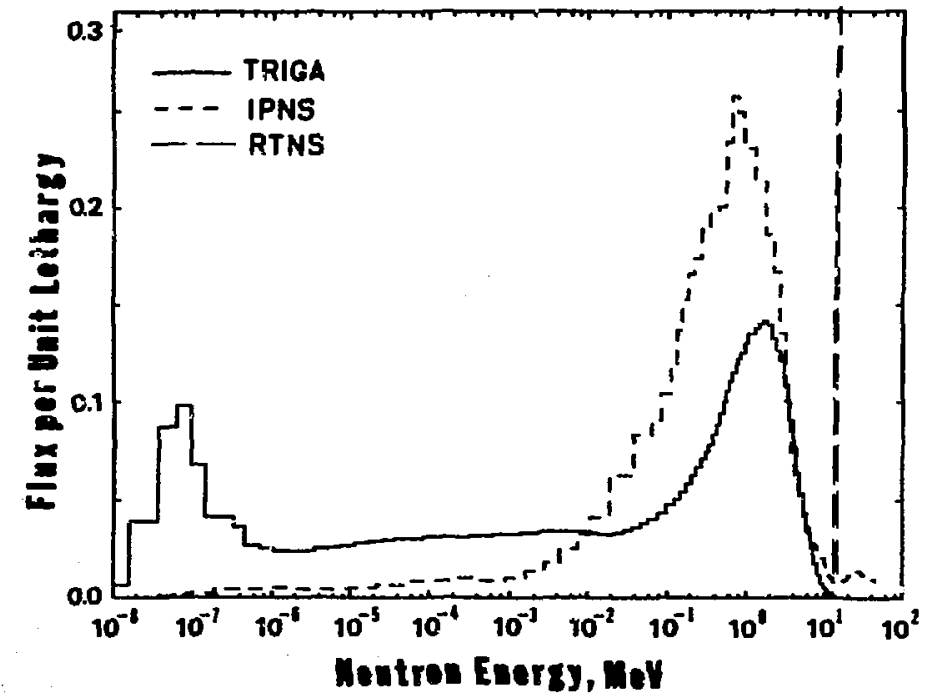

Fis. 1. Spectra of the neutron sourses used during the irradietions. 
Table 1. Flux densities of different neutron sources and calculated fusion reactor desigas, Units in $n / m^{2}$. $s$.

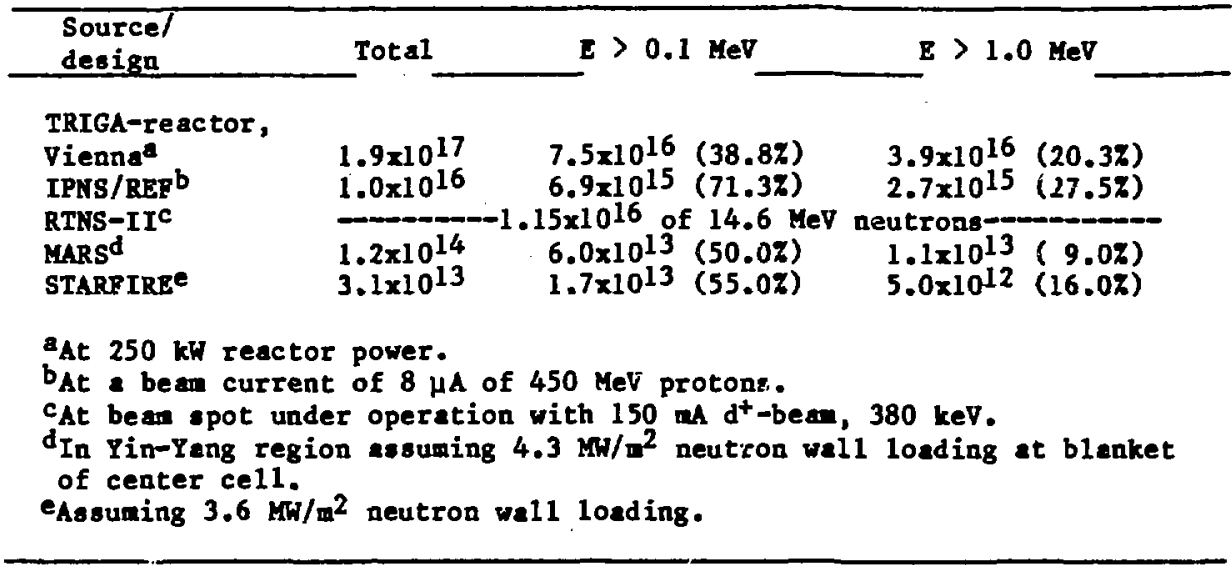

for both fusion reactor designs are fousd to be slightly snaller than those of the TRIGA-spectrum and are very close to the numbers obtained for IPIS.

Results

The results of all $j_{c}$-nessureatents prior and after the irradiations have been recorded and are available in files under VAX/VMS. The selection of data presented here primarily enphasizes the validity of danage energy scaling and also indicates the effect of neutron irradiation on naterials with different $T i-c o n c e n t r a t i o n$ and degree of final cold work (fcw). A more detailed analysis is given in Ref. 6 .

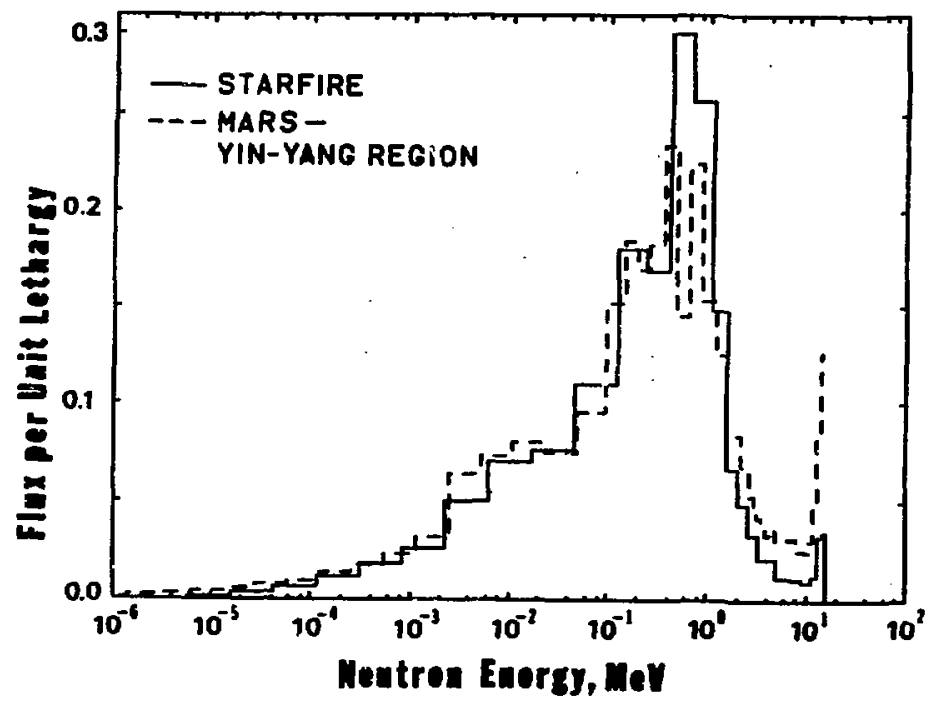

Fig. 2. Calculated neutron spectra st the nagnet location for two fusion reactor designs. 


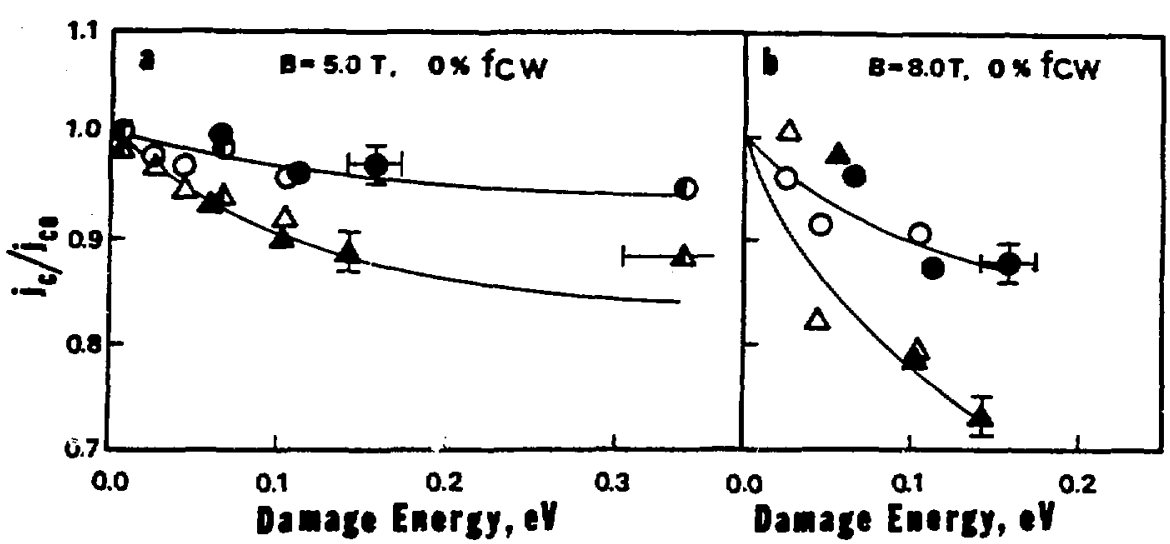

Fig. 3a. Fractional change of the critical current density $j_{c}$ at $4.2 \mathrm{R}$ and $5.0 \mathrm{~T} \mathrm{as}$ a function of the deposited damage energy for $\mathrm{Nb}-$

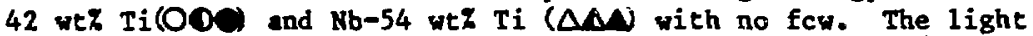
symbols represent the results of the irradiation at IPNS/REF, the shaded ones those of the TRIGA-reactor, and the bold ones those of the $14 \mathrm{MeV}$ neutron irradiation at RTNS-II

3b. Equivalent to $\mathrm{Fig}$. $3 \mathrm{a}$. but for $B=8.0 \mathrm{~T}$.

The fractional changes of $j_{c}$ as a function of the damage energy at $4.2 \mathrm{~K}$ and $5.0 \mathrm{~T}$ for all 3 irradiations are illustrated in Fig. 3a. The resulta for both $\mathrm{Nb}-42 \mathrm{wtz} \mathrm{Ti}(\mathrm{ODO})$ and $\mathrm{Nb}-54$ wtz Ti ( $\triangle \mathrm{N}$ ) fit a smooth line within the experimental uncertainties of the dosimetry results (+-10z) and of the quantity $j_{c} / j_{\text {co }}$ which depends slightly on the absolute value of the critical current $I_{c}$ (typically 27 ). The reasons for the observed differences in $j_{c}-$ degradation between $\mathrm{Nb}-42 \mathrm{wtz} \mathrm{Ti}$ and $\mathrm{Nb}-54$ wtz $\mathrm{Ti}$ are not completely understood at this time, particularly in consideration of the lacking final cold work in these materials which is required for a well de.ined microstructure and efficient flux pinning. As displayeed in Fig. 3b., this trend was found to be enhanced by a factor of about 3.0 at higher fields $(8.0 \mathrm{~T})$ where the performance of $\mathrm{Nb}-54 \mathrm{wtZ} \mathrm{Ti}$ dropped to $70 \%$ of its value prior to irradiation. We assume that a gradual change of the upper critical field $\mathrm{H}_{\mathrm{c} 2}$ during neutron irradiation is responsible. Hos has beep measured prior to irradiation, corresponding post-irradiation dita are still awaited

Table 2. Displacement damage energy cross sections $\left.\langle\sigma \cdot T\rangle_{E}\right\rangle 0.1 \mathrm{HeV}$ for different neutron sources and calculated fusion reactor designs, units in keV barn

\begin{tabular}{|c|c|c|c|c|c|c|}
\hline $\begin{array}{l}\text { Source } \\
\text { Design }\end{array}$ & $\mathrm{I}^{\prime} i$ & $\mathrm{Nb}$ & $\begin{array}{c}\mathrm{Nb}- \\
42 w+7 \mathrm{Ti}\end{array}$ & $\begin{array}{c}\mathrm{Nb}- \\
46.5 \mathrm{wtzTi}\end{array}$ & $\begin{array}{c}\mathrm{Nb}- \\
49 w \mathrm{tTi}\end{array}$ & $\begin{array}{c}\mathrm{Nb}- \\
54 w \mathrm{wTi}\end{array}$ \\
\hline
\end{tabular}

TRIGA-reactor,

$\begin{array}{lrrrrrr}\text { Vienna } & 81.5 & 70.7 & 76.9 & 77.4 & 77.7 & 78.2 \\ \text { IPNS/REF } & 64.9 & 62.0 & 63.7 & 63.8 & 63.9 & 64.1 \\ \text { RTKS-II } & 248.5 & 280.4 & 261.9 & 260.3 & 259.7 & 258.1\end{array}$

MARS,

$\begin{array}{lllllll}\text { Yin-Yang region } & 58.3 & 62.9 & 60.3 & 60.1 & 59.9 & 59.7 \\ \text { STARFIRE } & 66.5 & 67.9 & 67.0 & 67.0 & 67.0 & 66.8\end{array}$




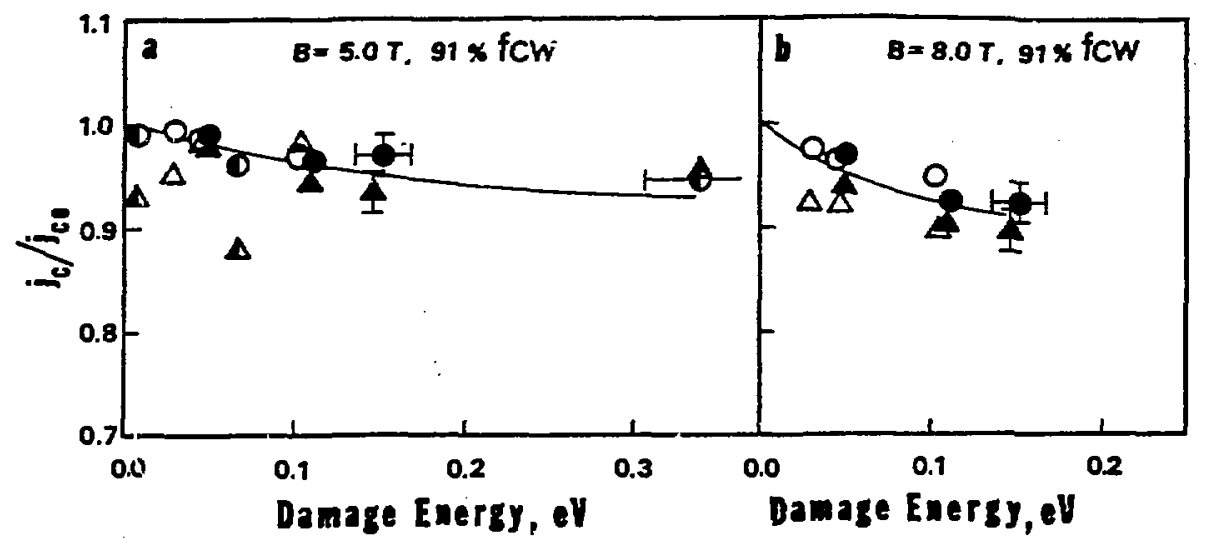

Fig. 4a. Fractional change of the critical current density $j_{c}$ at $4.2 \mathrm{~K}$ and $5.0 \mathrm{~T}$ as a functin of the deposited damage energy for heavily cold worked $\mathrm{Nb}-42$ wtZ $\mathrm{Ti}(\mathrm{OO})$ and $\mathrm{Mb}-54 \mathrm{wtz} \mathrm{Ti}$ ( $\triangle A N)$ the light symbols exhibit the results of the irradiation at IPNS/REF, the shaded ones those of the TRIGA-reactor and the bold ones those of the $14 \mathrm{MeV}$ neutron irradiation at RTNS-II. 4b. Equivalent to Fig. 4a. but for $B=8.0 \mathrm{~T}$.

In contrast, the response to neutron irradiation of heavily cold worked superconductors depicted in Figs. 4a. and 4b. is significantly smaller. Apparently their structure with a high density of dislocation cells and cell walls which is primarily responsible for an improvement in the flux pinnning mechanisa and consequently in $j_{c}$, is equal.ly affected by irradiation in both materials. Considering that the absolute increase in the normal state resistivity $p_{o}$ is roughly equal in both cold worked (Figs. 4a. and 4b.) and noncold worked $\mathrm{NbTi}$ (Figs. $3 \mathrm{a}$. and $3 \mathrm{~b}$. ), one expects higher $\mathrm{j}_{\mathrm{c}}$-degradiation in materials with $0 \% \mathrm{fcw}$. The change of $j_{c}$ can be written as

$$
\frac{\Delta f_{c}}{J_{c o}}=-c_{1} \frac{\Delta \rho}{\rho_{o}}+c_{2} \frac{\Delta H_{c 2}}{H_{c 2}}+c_{3} \frac{\Delta T_{c}}{T_{c}}
$$

with $j_{c o}, P_{o}, H_{c 2}$ and $T_{c}$ representing the values prior to irradiation. Our experimental observations demonstrate that $\mathrm{NbTi}$ with 07 fcw and initially lower $\rho_{o}$ are more affected by irradiation. A more detailed analysis of the effects of neutron irradiation with respect to the netallurgical parameters of NbTi superconductors will be presented later. For practical applications, the absolute value of $j_{c}$ prior to irradiation is as important as their performance during neutron irradiation, In cold worked (91\%) $\mathrm{Nb}-54 \mathrm{wt} \% \mathrm{Ti}, j_{c}$ was found to be $1.7 \times 10^{9} \mathrm{~A} / \mathrm{m}^{2}$ at $5.0 \mathrm{~T}$ and $0.61 \times 10^{9}$ $A / \mathrm{m}^{2}$ at $8.0 \mathrm{~T}$, whereas the same material with $0 \mathrm{fcw}$ yielded $8.3 \times 10^{8}$ and $2.2 \times 10^{8} \mathrm{~A} / \mathrm{m}^{2}$ respectively.

As further evidence for the validity of damage energy scaling, we present the results on the Swiss LCT-conductor in Fig. 5. At $8.0 \mathrm{~T}$, the highesc magnetic field in which ThTi superconductors are expected to be employed in projected magnet designs for fusion reactors, its performance decreases roughly 107 after half the lifetine fluence. 


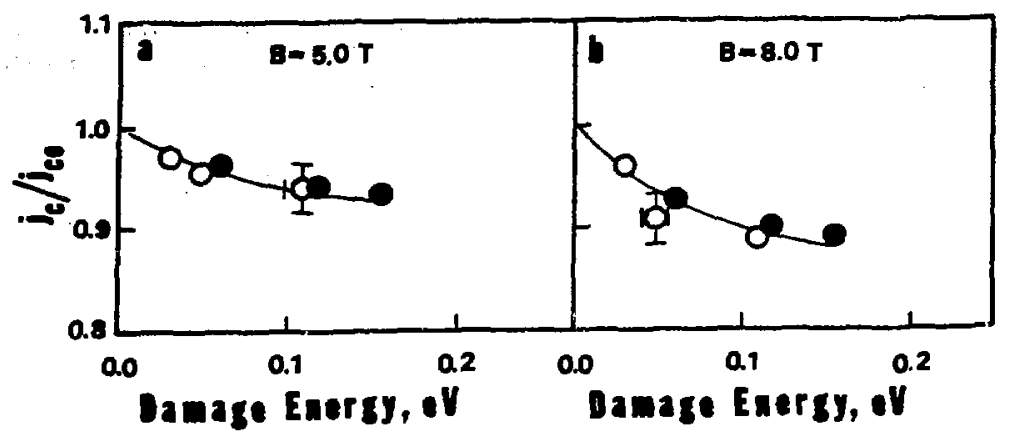

Fig. 5. Fractional change of $j_{c}$ at $4.2 \mathrm{~K}$ as a function of the deposited danage energy for the Swiss LCT-conductor. The light symbols represent the reault of the irradiation at IPNS/REF, the bold ones those of the $14 \mathrm{MeV}$ irradiation at RTNS.

\section{COHCLUSIONS}

In general, the results of all three irradiation experiments on $\mathrm{MbT}$ superconductors were found to agree when the obtained fluences are scaled with the appropriate danage energy cross sections. This experimental observation enables magnet designers to precisely determine the effects of neutron irradiation in magnet conponents since the effects of a fusion spectrun can be inferred from irradiations in other spectra. Considering technological applications of tbTi on a large scsle, waterials with multiple thermonechanical treatment are suited best for they have both higher initial critical current density and are least effected by irradiation.

\section{ACKMOWLEDGEMENTS}

The authors are gratefully indebted to the technical sesff of IPNS and RTNS-II for their support during the experinents and Ruth M. Nuckolls for handling the dosimetry. This work was performed under the auspices of the J.S. Department of Energy by Lawrence Livermore National Laboratory under contrace Mo. W-7405-Eng -48 and by the Federal Ministry of Science and Research, Wien, Austria.

\section{REFERENCES}

1. L. R. Greenwood, J. Nucl. Mater. $108 \& 109: 21-27$ (1982).

2. C. Lehmann in: "Interaction of Radiation with Solids and Elementary Defect Production," North Holland Publiahing Company, Arsterdam (1977), pp 88-92, pp 105-214.

3. "Evaluated Nuclear Data File, Version V," National Neutron Cross Section Center, Brookhaven National Laboratory (1979).

4. L. R. Greenwood and R. R. Smither, ANL/FPP/TM-197, Argonne National Laboratory, Argonne, IL 60439 (1985).

5. D. M. Parkin and C. A. Coulter, J. Nucl. Mater. 85 \& 86:611 (1979).

6. P. A. Hahn, Thesis, Technical University Vienna (1984), unpublished.

7. F. Mardai, H. W. Weber and R. R. Maix, Cryogenics 21: 223-233 (1981).

8. A. F. Clark and J. W. Ekin, IEEE Trans. Mag. 13 (1977).

9. F. G. Perey, "Least Squares Dosimetry Unfolding: The Program STaYSL," ORRL-TM-6062 (1977); nodified by L. R. Greenwood (1979).

10. H. W. Weber, H. Böck, E. Unfried and L. R. Greenwood, to be published in J. Nuc1. Mater.

11. "STARFIRE - A Comercial Tokanak Fusion Power Plant Study," C. C. Baker and M. A. Abdou, eds., AsL/FFP-80-1, vol. I \& 2 (1980).

12. "Mirror Advanced Reactor Study," JCRL-53480 (1984). 